\title{
Transvaginal Ultrasound Findings Among the Women Presenting with Infertility
}

\author{
Nafeesa Binti Hussain ${ }^{1 *}$ \\ Rinku Rani Das ${ }^{1}$ \\ 'Department of Obstetrics \& Gynaecology \\ BGC Trust Medical College \\ Chittagong, Bangladesh.
}

\begin{abstract}
Introduction: Infertility is a difficult conditions for the obstetricians to dealwith. Transvaginal ultrasound (TVS) is a investigation that is primarily done to evaluate the cases of infertility cases. The objective of the present study was to document the Transvaginal Scan (TVS) findings in women presenting with infertility in a teaching hospital of Bangladesh. Methods: Subjects were women of reproductive age presenting at the teaching hospital with infertility over a one year period. As part of their management, transvaginal scans was done. TVS was done by the researcher herself and was checked by a second observer. Data was complied and analyzed by SPSS 20. Results: Among the 100 cases regarding anthropometric variables where mean \pm SD of age was found $28 \pm 6.7$ years, weight was $56 \pm 12.5 \mathrm{~kg}$, height $1.57 \pm$ $0.76 \mathrm{~m}$ and BMI was $24.5 \pm 3.6 \mathrm{Kg} / \mathrm{m} 2$. Type of infertility revealed $75 \%$ cases were primarily infertile and $25 \%$ having secondary infertility. Comorbid diseases revealed $6 \%$ cases had DM, 4\% cases had HTN, 11\% cases had PID, 14\% patients had thyroid problems. All the 100 cases undergone TVS study where PCO was found among 69(69\%) cases, chronic pelvic inflammatory disease $14(14 \%)$ fibroids $6(6 \%)$ anatomical problems $19(19 \%)$ endometrial/cervical polyp $18(18 \%)$ free fluid in pelvic/abdominal cavity $7(7 \%)$ endometritis $5(5 \%)$ endometriosis $4(4 \%)$ adenomyosis $5(5 \%)$ chocolate cyst $8(8 \%)$ tubo-ovarian mass $2(2 \%)$ intrauterine and intra pelvic adhesions $2(2 \%)$ septate uterus $292 \%$ ) pelvic abscess $1(1 \%)$ and ectopic pregnancy $1(1 \%)$. Conclusions: Polycystic Ovaries (PCO) is the major finding in women with infertility in our study. This hitherto poorly recorded pathology should be actively investigated in women representing with these symptoms by the use of TVS.
\end{abstract}

Key words: Infertility; TVS; Ultrasound.

\section{INTRODUCTION}

Transvaginal sonography is a recent addition to the diagnostic techniques available for female pelvis. It is a cheap, quick, safe and reliable tool for solving diagnostic problems in women with gynaecological symptoms ${ }^{1,2}$.

The indications for gynaecological transvaginal sonography are palpable pelvic mass or suspicious of pelvic mass, confirmation of presence of an intrauterine contraceptive device in uterine cavity, post menopausal bleeding, suspicious of organic cause (eg. Submucousmyoma or endometrial polyp) bleeding in women before menopause suspicious of recurrent gyanecological cancer in the pelvis and suspicious of uterine malformation and also in infertility ${ }^{3,4}$.

Transvaginal sonography is performed with high frequency transducer placed in the vagina where it is in close anatomic proximity to pelvic structure and hence can see through pelvis, visualize the deeper structures and even note the fine details of organs like fallopian tube and ovary. In addition transvaginal sonography has become invaluable tool for care of infertility patients. Hence the need for the study is to re-affirm the role of transvaginal sonography and its diagnostic accuracy in various causes of primary and secondary infertility. 


\section{MATERIALS AND METHODS}

Patients attending Gyanecological Department of a tertiary care hospital, Bangladesh and admitted in wards for primary or secondary infertility during a three years study periods- were taken for the study. Detailed history, clinical examination and provisional clinical diagnosis was made then the patients are subjected to Transvaginal sonography examination and its role and accuracy studied. Ethical clearance has been obtained from the institution, there is a postgraduate committee consisting of head of the department, postgraduate professors in obstetrics and gynaecology department. Inclusion criteria for the study was primary \& secondary infertility and exclusion criteria was pregnancy and large pelvic masses. Transvaginal ultrasound was done the researcher herself. The model of the machine was (VOLUSON 730 Pro V. Made in JAPAN ). All data was collected and analyzed by SPSS- 20 .

\section{RESULTS}

Table 1: Anthropometric assessment $(n=100)$.

\begin{tabular}{lr} 
Variables & Mean \pm SD \\
Age & $28 \pm 6.7$ \\
Weight & $56 \pm 12.5$ \\
Height & $1.57 \pm 0.76$ \\
BMI & $24.5 \pm 3.6$ \\
\hline
\end{tabular}

Table 1 showing anthropometric variables where mean \pm SD of age was found $28 \pm 6.7$ years, weight was $56 \pm 12.5 \mathrm{~kg}$, height $1.57 \pm 0.76 \mathrm{~m}$ and BMI was $24.5 \pm 3.6 \mathrm{Kg} / \mathrm{m}^{2}$.

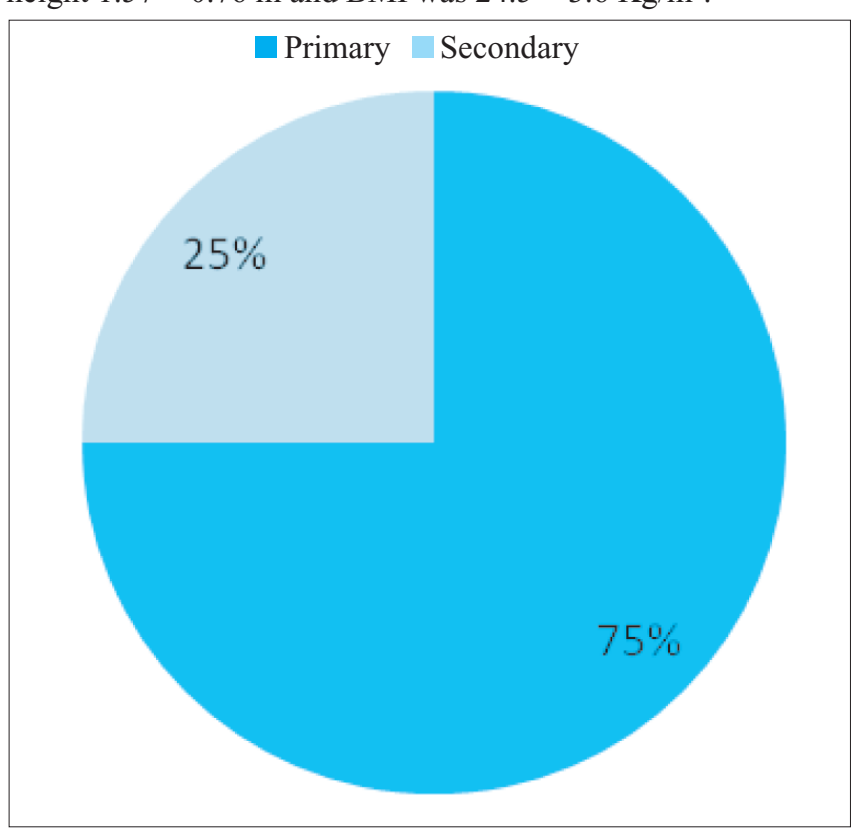

Figure 1: Type of infertility $(\mathrm{n}=100)$.

Figure 1 showing type of infertility where $75 \%$ cases were primarily infertile and $25 \%$ having secondary infertility.
Table 2 : Co morbid diseases $(n=100)$.

\begin{tabular}{lr} 
Comorbid diseases & $\mathbf{N}(\%)$ \\
DM (Diabetes Mellitus) & $6(6 \%)$ \\
HTN (Hypertension) & $4(4 \%)$ \\
PID (Pelvic Inflammatory Disease) & $11(11 \%)$ \\
H/O Tuberculosis & $2(2 \%)$ \\
Thyroid disorders & $14(14 \%)$ \\
Others & $8(8 \%)$ \\
No comorbidity & $55(55 \%)$ \\
\hline
\end{tabular}

Table 2 showing comorbid diseases where $6 \%$ cases had DM, $4 \%$ cases had HTN, $11 \%$ cases had PID, 14\% patients had thyroid problems.

Table 3 : General TVS findings $(n=100)$.

$\begin{array}{lr}\text { TVS study } & \text { Frequency (Percentages) } \\ \text { PCO (Polycystic Ovaries) } & 69(69 \%) \\ \text { Chronic pelvic inflammatory disease } & 14(14 \%) \\ \text { Fibroids } & 6(6 \%) \\ \text { Anatomical problems: Present } & 19(19 \%) \\ \text { Endometrial/Cervical polyp: Present } & 18(18 \%) \\ \text { Free fluid in pelvic/abdominal cavity: Present } & 7(7 \%) \\ \text { Endometritis } & 5(5 \%) \\ \text { Endometriosis } & 4(4 \%) \\ \text { Adenomyosis } & 5(5 \%) \\ \text { Chocolate cyst } & 8(8 \%) \\ \text { hydrosalpinx } & 2(2 \%) \\ \text { Tubo-Ovarian mass } & 2(2 \%) \\ \text { Oophoritis } & 1(1 \%) \\ \text { Intrauterine and intra pelvic adhesions } & 2(2 \%) \\ \text { Septate uterus } & 2(2 \%) \\ \text { Pelvic abscess } & 1(1 \%) \\ \text { Ectopic pregnancy } & 1(1 \%)\end{array}$

Table 3 showing TVS study findings among 100 patients of infertility where PCO was found among 69(69\%) cases, chronic pelvic inflammatory disease $14(14 \%)$, fibroids $6(6 \%)$ anatomical problems $19(19 \%)$ endometrial/cervical polyp $18(18 \%)$ free fluid in pelvic/abdominal cavity $7(7 \%)$ endometritis $5(5 \%)$ endometriosis $4(4 \%)$ adenomyosis $5(5 \%)$ chocolate cyst $8(8 \%)$ tubo-ovarian mass $2(2 \%)$ intrauterine and intra pelvic adhesions $2(2 \%)$ septate uterus $292 \%$ ) pelvic abscess 1(1\%) and ectopic pregnancy $1(1 \%)$. 
Table 4 : TVS findings of ovaries.

Ovarian parameters Findings Frequency (Percentages)

$\begin{array}{llc}\text { Ovarian volume } & \text { Normal } & 68(68 \%) \\ & \text { High } & 22(22 \%) \\ & \text { Low } & 10(10 \%) \\ \text { Follicular size } & \text { Normal } & 60(60 \%) \\ & \text { High } & 29(29 \%) \\ & \text { Low } & 11(11 \%)\end{array}$

Table 4 showing TVS findings of ovaries where $68 \%$ cases had normal ovarian volume and $60 \%$ had normal ovarian size. Volume was higher in $22 \%$ cases and $10 \%$ cases it was low, size was high in $29 \%$ cases and low in $11 \%$.

\section{DISCUSSION}

Present study was conducted in a Tertiary Care Hospital Chittagong, Bangladesh among 100 cases of infertile women during a study period of one year. Regarding anthropometric variables among the study women mean $\pm \mathrm{SD}$ of age was found $28 \pm 6.7$ years, weight was $56 \pm 12.5 \mathrm{~kg}$, height $1.57 \pm$ $0.76 \mathrm{~m}$ and BMI was $24.5 \pm 3.6 \mathrm{Kg} / \mathrm{m}^{2}$. Theses are common findings of Bangladeshi women as they have a bit little low height weight and BMI.

Regarding types of infertility where $75 \%$ cases were primarily infertile and $25 \%$ having secondary infertility. Infertility is a world-wide problem affecting people of all communities, though the cause and magnitude may vary with geographical location and socio-economic status. Approximately 15-20\% (2004) of couples within the reproductive age group present for medical assessment, generally following two years of failed efforts to reproduce. It is estimated that globally between 60-80 million couples suffer from infertility every year, of which probably between 15-20 million are in India alone. In India $40 \%$ infertile couples, the cause of infertility is the man, in $10 \%$, it is both the man and the woman ${ }^{4}$.

Regarding comorbid diseases revealed 6\% cases had DM, 4\% cases had HTN, 11\% cases had PID, 14\% patients had thyroid problems. Pregnancy is the result of a series of highly complex processes, which can be deranged by multiple disturbances on many different levels. Physicians are increasingly dealing with couples suffering from infertility. This rise in case numbers is mainly due to the fact that couples are more and more delaying childbearing until a later phase of their reproductive life, when their social and professional careers are established. The increasing mean age at the first birth has a negative impact on fertility by deteriorating quality and reducing the quantity of oocytes. With increasing age systemic diseases are becoming more coincidental, which in turn tend to exert negative effects on fecundity and fertility both in males and females. This review highlights some studies, associations between infertility and various common systemic diseases ${ }^{5-9}$.
Regarding TVS study findings among 100 patients of infertility where PCO was found among 69(69\%) cases, chronic pelvic inflammatory disease $14(14 \%)$ fibroids $6(6 \%)$, anatomical problems $19(19 \%)$ endometrial/cervical polyp $18(18 \%)$ free fluid in pelvic/abdominal cavity $7(7 \%)$ endometritis $5(5 \%)$ endometriosis $4(4 \%)$ adenomyosis $5(5 \%)$ chocolate cyst $8(8 \%)$ tubo-ovarian mass $2(2 \%)$ intrauterine and intra pelvic adhesions $2(2 \%)$ septate uterus $292 \%$ ) pelvic abscess $1(1 \%)$ and ectopic pregnancy $1(1 \%)$. In a study done by Niknejadi et al evaluated the diagnostic accuracy of transvaginal sonography in infertile patients and compared its results with hysteroscopy ${ }^{3}$. Transvaginal sonography is both cost effective and non-invasive method for the diagnosis of intrauterine lesions such as endometrial polyps. Anjali Singh et al studied the role of transvaginal sonography in dysfunctional uterine bleeding and its correlation with histopathology ${ }^{1}$. Transvaginal sonography could detect endometrial changes well correlated with histopathology in $92 \%$ cases and is a diagnostic tool for cases presenting with problems of dysfunctional uterine bleeding and can play a major role in diagnosis and management of dysfunctional uterine bleeding, as it has a greater patient compliance being a noninvasive OPD procedure. Amanda J.O. Leary et al studied the association between availability of transvaginal ultrasound examination in a general gynaecology clinic with fewer follow up visits and concluded that there is significant reduction in follow up rates for over $70 \%$ of patients seen in gynaecology clinics if transvaginal sonography is available at initial visits ${ }^{7}$. Anita S.Y. Sit et al studied the use of transvaginal sonography for evaluation of abnormal vaginal bleeding $^{8}$. As endometriosis responds to estrogens, endometrial thickness may constitute the biomarker of estrogen status in post menopausal women. So it can be said that TVS can be used safely in the diagnosis of infertility in our context.

Infertility treatment involves more complicated, uncomfortable, and humbling medical procedures for women, so the coping strategies used by wives may differ from those used by husbands. In particular, many studies underscore that treatments for assisted conception, and particularly IVF, which is the most studied of these, are a source of stress for the couple who make a great emotional investment in these treatmentssadness, depression, anxiety hopelessness, and anger are common in infertile couples underwent IVF treatment. The emotional distress is particularly great when waiting for treatment outcome, in the case of unsuccessful treatment and in the cycles following the first attempt it also depends on the ability of the couple to cope with this condition ${ }^{10-16}$.

\section{CONCLUSION}

Infertility treatments are more complicated, uncomfortable, and humbling medical procedures for women. So investigation like TVS can play a great role in initial diagnosis of infertility in a low economic setting like Bangladesh.

\section{DISCLOSURE}

Both the authors declared no competing interest. 
REFERENCES

1. Anjali Singh, SurajSngh, VeenaMathur. Transvaginal sonography in dysfunctional uterine bleeding its correlation with histopathology. J. of obstetrics and gynaecology of India. 2001;51.

2. A. Sokalska, D. Timmerman, A.C. Testa, C. Van Holsbeke, A.A. Lissoni, F.P.G. Leone, D. Jurkovic and L. Valentin. Diagnostic accuracy of transvaginal examination for assigning a specific diagnosis to adnexal masses. USG obstet gynecol. 2009; 34: 462-470.

3. Maryam, Niknejadi, Firoozeh Ahmadi, Fatemah Zafarani, Gholamreza Khalili, Farahnaz Ghaderi, Zohreh Rashidi. Diagnostic Accuracy of Transvaginal sonography in infertile patients with endometrial polyps. International J. of fertility and sterility. 2010;3(4):157-160.

4. Dhillon, R., Cumming, C.E. and Cumming, D.C. Psychological well-being and coping patterns in infertile men. Fertiityl. Sterilization. 2000; 74: 702-706.

5. Sartorius GA, Bürgin L, Kaufmann F, De Geyter C Comorbidity in infertile couples TherUmsch. 2009 ;66(12):779-787.

6. Bazot M, Thomassin I. Hourani R, Cortez A, Darai E. Diagnostic accuracy of transvaginal sonography for deep Pelvic endometriosis. Ultrasound obstet. Gynecol. 2004;24(2): 180-185.

7. Amanda J. O' Leary, Sanjay K. Vyas. Association between availability of transvaginal ultrasound examination in a general gynaecology clinic with fewer follow up visits. Gynecol. Surg. 2006 ; 3(1): 15-17.

8. Anita S.Y. Sit, Francesmarymodugno, Lyndon, M. Hill, Jerry Martin and Joel L. Weissfeld. Transvaginal ultrasound measurement of endometrial thickness as a Biomarkes for estrogen exposure. Cancer epidemiology, Biomarkers and prevention. 2004; 13: 1459.

9. Elsie Kiguli-Malwadde and Rosemary K Byanyima, Structural findings at hysterosalpingography in patients with infertility. Afr Health Sci. 2004; 4(3): 178-181.

10. Komori S, Fukuda Y, Horiuchil,Tanaka H, Kasumi H, Shigeta M et al. Diagnostic laparoscopy in infertility. J LaparoendoseAdvSurg Tech A. 2003; 13: 147-151.

11. A.A. Osman. Management of Infertility within Primary Health Care Program in Sudan. Asian Journal of Scientific Research. 2011; 4: 158-164.

12. Lavanya Rajashekar, Deepika Krishna, and Madhuri Patil. Polycystic ovaries and infertility. J Hum Reprod Sci. 2008;1(2): 65-72.

13. Brennan D. Peterson, M.S. Examining Congruence Between Partners' Perceived Infertility-Related Stress and Its Relationship to Marital Adjustment and Depression in Infertile Couples Family Process. 2004; 42(1): 59 - 70.

14. Lee, sun G.H. Development of the coping scale for infertile couples Archives of Andrology. 2003;45(3): 149-154.

15. Cousineau. T. A multimedia psychosocial support program for couples receiving infertility treatment: A feasibility study. Fertility and Sterility. 2003;81(3): $532-538$.

16. Nyboe and Andersen A. Evaluation of a communication and stress management training programme for infertile couples.PatientEducCouns. 2005;59(3):252-262. 